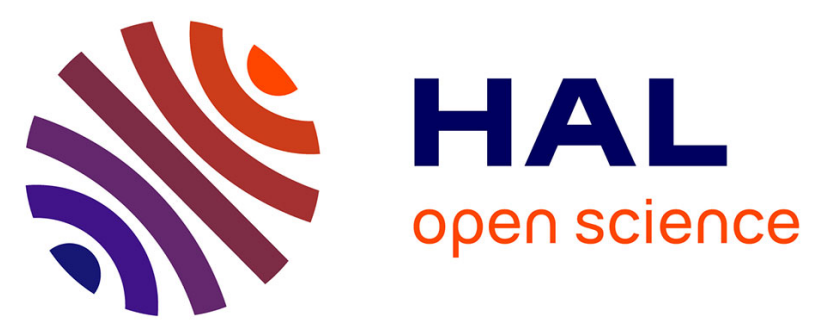

\title{
Characteristic atmosphere-ocean-solid earth interactions in the Antarctic coastal and marine environment inferred from seismic and infrasound recording at Syowa Station, East Antarctica
}

Masaki Kanao, Alessia Maggi, Yoshiaki Ishihara, Eléonore Stutzmann, Masa-Yuki Yamamoto, Genti Toyokuni

\section{To cite this version:}

Masaki Kanao, Alessia Maggi, Yoshiaki Ishihara, Eléonore Stutzmann, Masa-Yuki Yamamoto, et al.. Characteristic atmosphere-ocean-solid earth interactions in the Antarctic coastal and marine environment inferred from seismic and infrasound recording at Syowa Station, East Antarctica. The Geological Society, London, Special Publications, 2013, pp.SP381.8. 10.1144/SP381.8 . hal-00825141

\section{HAL Id: hal-00825141 \\ https://hal.science/hal-00825141}

Submitted on 23 May 2013

HAL is a multi-disciplinary open access archive for the deposit and dissemination of scientific research documents, whether they are published or not. The documents may come from teaching and research institutions in France or abroad, or from public or private research centers.
L'archive ouverte pluridisciplinaire HAL, est destinée au dépôt et à la diffusion de documents scientifiques de niveau recherche, publiés ou non, émanant des établissements d'enseignement et de recherche français ou étrangers, des laboratoires publics ou privés. 


\title{
Characteristic atmosphere-ocean-solid earth interactions in the Antarctic coastal and marine environment inferred from seismic and infrasound recording at Syowa Station, East Antarctica
}

\author{
Masaki Kanao ${ }^{1}$, Alessia Maggi ${ }^{2}$, Yoshiaki Ishihara ${ }^{3}$, \\ Eleonore Stutzmann ${ }^{4}$, Masa-yuki Yamamoto ${ }^{5}$ and Genchi Toyokuni ${ }^{6}$
}

${ }^{1}$ National Institute of Polar Research, Research Organization of Information and Systems, 10-3, Midori-cho, Tachikawa-shi, Tokyo 190-8518, Japan, Tel; +81-42-512-0713, Fax; +81-42-5283479; E-mail; kanao@nipr.ac.jp

${ }^{2}$ Institut de Physique du Globe de Strasbourg, CNRS and University of Strasbourg, 5 rue Rene Descartes, F-67084 Strasbourg Cedex, France, Tel; 33-3-6885-5028, Fax; 33-3-6885-0125, Email; alessia.maggi@unistra.fr

${ }^{3}$ National Astronomical Observatory, National Institutes of Natural Sciences, 2-12 Hoshigaokacho, Mizusawa-ku, Oshu, Iwate 023-0861, Japan, Tel; +81-197-22-7149, Fax; +81-197-227120, E-mail; ishihara@miz.nao.ac.jp

${ }^{4}$ Institut de Physique du Globe de Paris, Bureau 304, 1 rue Jussieu, 75238 Paris Cedex 05 France, Tel; 33-1-8395-7480, Fax; 33-1-8395-7480, E-mail; stutz@ipgp.fr nipr.ac.jp

${ }^{5}$ Kochi University of Technology, 185 Miyanokuchi, Tosayamada-cho, Kami-shi, Kochi 782-8502, Japan, Tel; 81-887-53-1111, Fax; 81-887-57-2000, E-mail; yamamoto.masa-yuki@kochitech.ac.jp

${ }^{6}$ Research Center for Prediction of Earthquakes and Volcanic Eruptions, Graduate School of Science, Tohoku University, 6-6 Aza-Aoba, Aramaki, Aoba-ku, Sendai 980-8578, Japan, Tel; +81-22-795-4385, Fax; +81-22-264-3292, E-mail; toyokuni@ aob.gp.tohoku.ac.jp

Running Title: Microseisms and Microbaroms in East Antarctica 
Abstract: Several characteristic waves detected by seismographs in Antarctic stations have been recognized as originating from the physical interaction between the solid-earth and the atmosphere ocean - cryosphere system surrounding the Antarctic and may be used as a proxy for characterizing ocean wave climate. A Chaparral type infrasound sensor was installed at Syowa Station (SYO; 39.6E, 69.0S), East Antarctica, in April 2008 during the International Polar Year (IPY2007-2008). Matching data are also available for this time period from the existing broadband seismic recorder located close by. Continuous infrasound data for 2008-09 includes background signals (microbaroms) with a broad peak in the wave period between the values of 4 and 10 seconds. Signals with the same period are recorded by the broadband seismograph at SYO (microseisms). This period band is identified as Double-Frequency Microseisms/baroms (DFM). The DFM has relatively lower amplitudes during winter. We suggest that this is due to the sea-ice extent around the coast causing a decreased ocean loading effect. In contrast, the Single Frequency Microseisms/baroms (SFM) with a peak in period between 12 and 30 seconds are observed under storm conditions, particularly in winter. On the infrasound data, stationary signals are identified with harmonic overtones at a few $\mathrm{Hz}$ to lowermost human audible band, which we suggest is due to local effects such as sea-ice cracking and vibration. Microseism measurements are a useful proxy for characterizing ocean wave climate, complementing other oceanographic and geophysical data. At SYO, continuous monitoring by both broadband seismograph and infrasound contributes to the Federation of Digital Seismographic Networks, the Comprehensive Nuclear-Test-Ban Treaty in the high southern latitudes, and the PanAntarctic Observations System under the Scientific Committee on Antarctic Research.

Keywords: atmosphere - ocean - solid earth system, microseisms / microbaroms, wave propagation, physical interaction, environmental monitoring, global network, East Antarctica 


\section{Introduction}

In the half-century after the International Geophysical Year (IGY; 1957-1958), the number of global seismic network and other seismic stations has increased in Antarctica. The Japanese Syowa Station (SYO; 69S, 39E), East Antarctica, has contributed data since 1959 (Eto, 1962). A three-component broadband seismometer (STS-1; Wielandt and Steim, 1986) was installed in 1989, as SYO joined the Federation of Digital broadband Seismographic Network stations (Butler and Anderson, 2008; Fig. 1). The density of both permanent stations belonging to the global network and temporary stations deployed at specified locations has improved over time, and has recently permitted studies of local seismicity in the Antarctic (Reading, 2006; Reading , 2007; Kanao et al., 2006). Most recently, the 'Polar Earth Observing Network (POLENET; http://www.polenet.org)' has made a significant contribution of the International Polar Year (IPY2007-2008) towards improving broadband seismic-recording in Antarctica.

Several kinds of environmental signals associated with the atmosphere, notably the ocean - solid earth system, have been detected in Antarctica and the surrounding regions. Seismic motions for small magnitude ice-related events are generally named 'ice-quakes' (or 'ice-shocks') and can be generated by glacier dynamic activity (Anandakrishnan et al., 2003; Kanao and Kaminuma, 2006). Such cryoseismic sources include the movements of ice sheets, ice sheets, glaciers, sea ice, oceanic tide-cracks, oceanic gravity waves, icebergs and the calving process. Cryoseismic sources are likely to be influenced by environmental conditions, and the study of their temporal variation may provide indirect evidence of climate change.

Almost all the seismic stations deployed on the Earth's surface record ubiquitous signals at periods of between 4 and 25 seconds, commonly referred to as "microseisms". In the absence of large earthquakes, microseismic waves are the strongest-amplitude signals worldwide, including the polar regions. Microseisms are considered to be dominated by Rayleigh waves, which arise from gravity waves in the ocean that are forced by surface winds. The period ranges of microseisms are dictated by the physics of gravity-wave generation, and are constrained by the speed and extent of Earth's surface winds (Aster et al., 2008; Bromirski, 2009; Ardhuin et al., 2011). On a global scale, microseism amplitudes are generally highest during the local winter, because nearby oceans are stormier in winter than in summer (Stutzmann et al., 2009). Within the polar regions, particularly in Antarctica, there is no clear picture of the behaviour of microseisms in space and time. Recently the seasonal trend has been found to be reversed, most probably because of the effect of winter sea-ice (Stutzmann et al, 2009; Grob et al, 2011).

Alongside global seismic stations, there is a smaller but increasing number of infrasound stations. Infrasound is defined as sub-audible sound, that is pressure waves with frequencies ranging from the cut-off frequency of sound $\left(3.21 \mathrm{mHz}\right.$, for a $15^{\circ} \mathrm{C}$ isothermal atmosphere) to the lowest frequency of the human audible band $(20 \mathrm{~Hz})$. This frequency range is a new horizon for the remote sensing of the Earth's atmospheric physical environment, and shares the same frequency range as the broadband seismometer. It is known that Earth's free vibrations can excite similar modes in the upper atmosphere. The great Sumatra-Andaman earthquake of 26 December 2004 not only produced the seismic waves that were recorded as far as Antarctic stations (Nawa et al., 2007), but also produced infrasound waves that were recorded after propagating through 
the atmosphere (Iyemori et al., 2005). Another example of simultaneous observation of infrasound and seismic signals concerns the shock waves generated by a meteorite that passed over Japanese Island (Ishihara et al, 2004). Continuous infrasound observation was started at SYO as one of the projects of IPY2007-2008, and in addition to the four existing test-ban treaty network certified Antarctic infrasound stations at Davis (Australia), Windless Bight (near McMurdo, USA), Palmer (USA) and Neumayer (Germany).

In this paper, several features of seismic and infrasound wave-propagation in the continental margin of East Antarctica are illustrated by using the data at SYO (Fig. 2). Background infrasound signals (microbaroms) with peak amplitudes at periods of 4 and 10 seconds are analyzed, and compared with those recorded by broadband seismographs (microseisms). Loading effects from the Southern Ocean are investigated through analysis of time-dependent variations of amplitudes and frequency content of power spectral densities (PSD). The oceanic effects on seismic and infrasound data are modulated by the presence of sea-ice, and can therefore be related to the polar atmosphere-ocean-cryosphere system. Measurements of microseisms / microbaroms are a useful proxy for characterizing ocean-wave climate and global storm intensity, with help to reveal the physical interactions between these multi-spheres. Moreover, it provides an indicator of the extent of very recent environmental change, as inferred from Antarctica.

\section{Microseisms recorded at Syowa Station}

In general, the microseism spectrum has a bimodal composition, caused by the existence of two distinct physical mechanisms that transfer ocean-wave energy to seismic waves in the geosphere (Fig. 2). The first spectral peak between approximately 12 and 30 s, commonly called "primary" or "single-frequency microseism (SFM)", arises from the transfer of ocean-gravity wave (swell) energy to seismic waves as oceanic waves shoal and break in the shallow waters. The highest amplitude and longest period swells are created by large and intense storms that generate strong sustained winds over a large area. Swell propagates dispersively across ocean basins, which results in a longer period swell arriving at the coast before the shorter period swell. This period-dependent delay is readily measured in data recorded by seismic stations, ocean buoys, and seismographs, even those deployed recently on a giant Antarctic iceberg (MacAyeal et al., 2009).

The second, more prominent, microseism peak between approximately 4 and $10 \mathrm{~s}$, commonly called "secondary" or "double-frequency microseism (DFM)", arises from nonlinear interaction of interfering oceanwave components that produce a pressure pulse at double their frequency. This pressure pulse propagates with little or no attenuation to the sea floor where it generates seismic waves. The DFM is thought to be generated both near the coasts, where coastal swell reflection can provide the requisite opposing wave components, and to a lesser extent also in the deep ocean (Fig. 2).

On a global scale, microseism amplitudes are generally highest during the local winter, because nearby oceans are stormier in winter than in summer (Stutzmann et al., 2009). In Antarctica, the opposite observation is made: microseism amplitude is attenuated during the local winter for both primary and secondary microseisms (Hatherton, 1960; Grob et al, 2011). Figure 3 represents examples of short-period seismograms (HES; 
Hagiwara, 1958) recorded at SYO, during both the austral summer (Fig 3d) and winter (Fig 3e) of 1997. Microseisms with their dominant frequency of a few seconds are recognized clearly throughout the austral summer recording, and are missing on the winter recording. These observations are most readily explained by winter sea ice impeding both the direct ocean-to-continent coupling that generates the SFM, and the coastal reflection which is an important component in the generation of the DFM (Grob et al., 2011).

In order to illustrate the variability of microseismic amplitude over time, we analyze the power spectral density (PSD) for data from the STS-1 seismometer at SYO. During the time period investigated in this paper, the data were continuously sampled at $20 \mathrm{~Hz}$ and transmitted from SYO to the National Institute of Polar Research (NIPR) by an Intersat telecommunication system (Aoyama and Kanao, 2010). Figure 4 represents the PSD of the vertical component of ground motion during a typical austral summer day in November, 2010. In spite of the presence of large teleseismic signals towards the end of the day, the DFM is clearly visible with sufficient amplitude through the whole time period. Figure 5 represents similar PSDs for the whole year of 2004 over the period band 0.1-80 s (modified after Grob et al, 2011; Kanao et al., 2012). The DFM is in general more strongly excited when storms or blizzards visit the station, and to a large degree is probably generated in vicinity of the Lützow-Holm Bay. The DFM can be identified all year round, although with distinctly lower amplitude during the local winter (April - October). The relatively high degree of inter-annual variability presumably reflects the large influence of extratropical cyclonic storms that commonly affect both the northern and southern oceans. On the contrary, the SFM is observed only under excellent storm conditions during the austral local winter. The strength of both DFM and SFM are strongly related to the seasons, but presumably also to the local sea-ice conditions in vicinity of the station. For example, summers with lower amplitude microseisms at SYO seem to correspond to the presence of residual sea-ice near the Enderby Land coast (see Grob et al, 2011).

Figure 6 shows in more detail the microseismic spectra over a year in 2007 for both SYO and Casey stations in East Antarctica (modified after Grob et al, 2011). Each curve represents the seismic noise spectrum for one day, and is colour coded by day of the year. Primary (SFM) and secondary (DFM) microseisms are outlined by boxes. The peak frequencies of the SFM are highlighted in red and blue, for local summer and winter respectively. At both stations, it can be clearly seen that the spectral amplitudes for the SFM decrease during local winter, and migrate to longer periods.

An important parameter monitored by station operators is the teleseismic detectability, i.e. the capability of a station to detect a seismic event occurring at teleseismic distances (over $30^{\circ}$ away). This parameter is strongly correlated to the noise level at the station. Temporal variations in teleseismic detectability at SYO were investigated for the period from 1987 to 2007 (Kanao, 2010). During the austral summer, the station shows less teleseismic detectability (i.e. the station detects fewer low-magnitude events) than during the austral winter, because of high noise level in the local summer arising from both natural factors and human activity close to the station. These variations in teleseismic detectability also indicate a strong relationship with the surrounding environment, such as meteorological events, sea-ice thickness and its spreading area (Ushio, 2003), and more particularly the amplitude of microseisms which is strongest during the austral summers. 


\section{Microbaroms observed during the IPY}

Over the last few decades, in order to monitor the nuclear tests, a global infrasound network has been constructed by the Comprehensive Nuclear-Test-Ban Treaty Organization (Fig. 7-top; Butler and Anderson, 2008). One objective of the Treaty is to estimate the detection and location capabilities of this network at regional and global distances. Another is to explore ways to improve these capabilities and enhance the understanding of wave propagation through the atmosphere of the observed events. At this time, the test-ban treaty network has sixty infrasound stations, each containing at least four sensors (array stations), that can detect a several-kilotonne TNT-level explosion at a range of $\sim 1000 \mathrm{~km}$. Although the full capability of the global infrasonic network is yet to be established, it is fully adequate for monitoring nuclear tests, but too sparse for analyzing natural infrasound phenomena in detail.

In April 2008, a Chaparral-type sensor was installed on a rock outcrop at SYO (Fig. 7a,b) as a project of the International Polar Year of 2007-2008 (Ishihara et al., 2009), making Syowa the fifth permanent infrasound station in Antarctica. From the analysis of $100-\mathrm{Hz}$ trial data recorded at SYO during two winter seasons in 2008-2009, we found continuous background infrasound noise (Figs. 8-10) which appear to correspond to co-oscillation with the DFM and SFM as observed by seismographs at SYO. Although the DFM is widely recorded, the single-frequency microbarom (SFM), arising from the direct transfer of ocean-gravity wave (swell) energy to infrasonic waves, has not been recorded to date. Theory predicts radiation of DFM into the atmosphere from microbarom source process, but theory does not predict for the SFM (Waxler and Gilbert, 2006). Time variations similar to those observed on seismic spectra are also observed in infrasound data, and also seem to correlate with storms that occur with intervals of a few days (as indicated by the strong energy arrivals in Figures 8 and 9). These observations suggest the presence of physical interaction between the atmosphere - ocean system and the solid earth in the microbarom (microseism) frequency ranges. In addition to the microseisms, characteristic repeating signals over $10 \mathrm{~Hz}$ with harmonic over-tones are occasionally recorded as indicated by broken green squares in these figures.

Figure 8 represents the PSD of infrasound signals at SYO for one day during austral summer in January 2010. The DFM frequency is indicated by a red arrow, and varies significantly both in amplitude and frequency content over the day. These variations may correspond to atmospheric variations related to changes in weather conditions in the surrounding Lützow-Holm Bay. High-frequency repeating signals above $10 \mathrm{~Hz}$ with harmonic overtones are once more identified,and indicated by a broken green square. The harmonic overtone signals may be associated with local phenomena, such as katabatic winds, or with ice dynamics caused by various environmental changes near the station (i.e. sea-ice movement, tide-crack opening shocks, iceberg tremors, basal sliding of the ice-sheet and calving of glaciers, etc.). The other explanation for signal of "high-frequency harmonic signals" is resonance effects in infrasound pipes used as a wind filter at the station. For example, a resonance effect in pipes is discussed in Hedlin and Alcoverro (2005). 
Loading effects from the Southern Ocean are clearly recorded by both broadband seismographs and infrasound sensors deployed at SYO. The oceanic effects on infrasound will be modulated in the same way as for the seismic data by the presence of sea ice, and are even more directly related to the atmosphere-oceancryosphere system. The measurements of "microbaroms" may therefore be a useful parameter for characterizing ocean-wave climate and global storm intensity, complementing other estimates from oceanic or satellite measurements. The infrasound data at SYO, moreover, contains signals with harmonic overtones of uncertain origin, but which may be related to the ice dynamics in the Antarctic. Monitoring the infrasound waves could therefore be a new way to record regional environmental changes in Antarctica.

For further investigation, a theoretical modelling approach is required to determine the actual sources of several kinds of infrasound signals. It would be also useful to compare these signals in more detail with other data, such as broadband seismograms that share sensitivity over part of the infrasound frequency range. The array alignment of the infrasound stations, moreover, could firmly provide robust information about the arrival direction and epicentral distance from the infrasound sources. Additional observations with an array station near the current SYO station would be helpful.

\section{Cryosphere wave signals}

Over the past few decades, more seismic observations in the polar regions by both temporary seismic networks and permanent stations have detected local seismicity. Seismic signals involving ice-related phenomena are called "ice-quakes" (ice-shocks for smaller ones), and are most frequently reported in association with glacier-related mass movements of ice sheets, or with sea ice, tide-cracks and icebergs (Anandakrishnan and Alley, 1997; Kanao and Kaminuma, 2006; Wiens, 2007; Nettles and Ekström, 2010). The so-called "icemicity" detected around the Bransfield Strait and Drake Passage by a local network of hydrophone arrays in 2006-2007 illustrated the dynamic behaviour of sea ice in the Antarctic Peninsula (Dziak et al., 2009). Local seismicity around the Lützow-Holm Bay was reported by Kanao and Kaminuma (2006), who detected seventeen events using a local network deployed around the Bay. Most of the hypocentres were located along the coast, apart from a few on the northern edge of the continental shelf. Several of these events may have been large icequakes associated with the sea-ice around the Lützow-Holm Bay or in the Southern Ocean.

Sea-ice dynamics and icebergs clearly affect seismic signals. A large volume of sea ice was discharged from Lützow-Holm Bay during the 1997 austral winter, and was clearly imaged by the NOAA satellite (Ushio, 2003). The broadband seismographs at SYO recorded distinct waveforms associated with the discharge events. The long-duration sea-ice tremors had very distinct spectral characteristics that distinguished them clearly from ordinary teleseismic events, together with local tectonic events. Several sequences of signals with strong harmonic overtones, presumably associated with the merging of multiple ice volumes, appeared on the PSDs. The PSDs also showed surge events that seemed more closely related to the break-up process of the sea-ice mass. Both kinds of cryoseismic waves occurred continuously for few hours, and repeated themselves several times within a few days during late July, 1997. 
Similar cryoseismic phenomena have also been reported around the Ross Sea region (MacAyeal et al., 2009), the marginal sea of the Antarctic Peninsula (Bohnenstiehl et al., 2005; Dziak et al., 2009), as well as the continental margin of Dronning Maud Land (Muller and Eckstaller, 2003). In particular, iceberg-originated harmonic tremor emanating from tabular icebergs has been observed by both seismo-acoustic and local broadband seismic signals (MacAyeal et al., 2009). The tremor signals consisted of extended episodes of stickslip ice-quakes generated when the ice-cliff edges of two tabular icebergs rubbed together during a glancing, "strike-slip" collision. Source mechanisms of such harmonic tremors might provide useful information for the study of iceberg behaviour, and a possible method for remotely monitoring iceberg activity.

However, it should also be pointed out that in addition to these cryoseismic phenomena, several small- to middle-magnitude local/regional natural seismic events have been recorded. Unfortunately, many of these could not be located accurately, since they have unclear arrivals when recorded by the present global network, which is particularly sparse near Antarctica.

\section{Interaction of the atmosphere-ocean-solid earth system}

Most of the community agrees that the Polar Regions play a critical role in the Earth's system. The Southern Ocean and the Antarctic ice sheet and its response to climate change potentially have a great impact upon humanity, through both long-term sea-level rise and modulation of fresh-water input to the oceans. Monitoring the dynamic response of the polar ice sheets between the ocean and atmosphere, as well as the underlying solid Earth, should be important components in a long-term effort to observe climate change on a global scale. Future directions and targets in the global monitoring effort will probably emerge from multidisciplinary projects combining data from several global networks. For example, it would be useful to compare infrasound signals with other data, such as broadband seismograms and hydro-acoustic waves that share sensitivity over part of the infrasound frequency range.

There is still much to be learned about the physical mechanisms of interaction between the atmosphere ocean - cryosphere - solid Earth system in Antarctica. Continuous observation by a sufficiently large number of high-quality monitoring stations, as well as theoretical work, will probably be necessary to make progress in this field. Given the high cost and technical difficulties of continuous observation in the Antarctic, such work would require strong international collaboration beyond the end of the International Polar Year.

\section{The place of Antarctica in the global network}

In previous sections, we discus the information that that seismic data contain regarding wave activity, icedynamics and weather-related phenomena (e.g. storms). Continuous digital records from the global seismographic network (Fig. 1), and their precursor networks extend back more than 40 years, and hence open up the possibility of using seismic data from Antarctica to investigate climate change and palaeoenvironments. 
A large seismology research programme consisting of several field-campaigns was held during the IPY2007-2008 and in order to complement the network of permanent stations at the high latitudes in the Polar Regions. In Antarctica, the most ambitious seismological field campaign conducted for the IPY was the "Gamburtsev Mountain SEISmic experiment" or GAMSEIS, an internationally co-ordinated deployment of more than 50 broadband seismographs over the crest of the Gamburtsev Subglacial Mountains in East Antarctica (Wiens, 2007; Hansen et al., 2010). GAMSEIS and many other seismological deployments, including a French deployment between Concordia and Vostok Lake (CASE-IPY), and a Japanese deployment around SYO (GARNET), were co-ordinated under the larger programme called POLENET. Some of the stations installed for these campaigns are destined to remain deployed well into the future, and this network will be as one of the Internatioinal Polar Year's most significant legacy.

These seismic networks, together with the infrasound stations in the Antarctic, strongly contribute to both the test-ban treaty network (Fig. 7) and the Pan-Antarctic Observations System under the Scientific Committee on Antarctic Research. Hydro-acoustic observations contribute to the understanding of wave-propagation inside the ocean, and have already been exploited to investigate seismicity and sea-ice dynamics around the Bransfield Strait, Antarctic Peninsula (Dziak et al., 2009). The combination of seismic, infrasound and hydro-acoustic observations is most likely required to understand in more detail the atmosphere-ocean-cryosphere-solid Earth system and its variations with time. We are hopeful that the large quantity of data of these three types accumulated over the past decades by the test-ban treaty network will soon be distributed to the scientific community in order to advance research in this domain.

\section{Conclusions}

Several characteristic features of seismic and infrasound waves propagating in the coastal region of East Antarctica, and how they are related to the atmosphere-ocean-solid Earth system, are treated in this paper. Microseisms and microbaroms originating sfrom the Southern Ocean are clearly recorded by both the broadband seismograph and infrasound sensor deployed at SYO, in the Lüztow-Holm Bay, East Antarctica.

The double frequency microseism / microbarom (DFM, with peaks at 4-10s period) reflects the large influence of extratropical cyclonic storms that commonly affect the southern oceans. It can be identified all year round, although with distinctly lower amplitude during austral winter, presumably because of the large sea-ice extent and the consequent reduction in oceanic loading. The single frequency microseism / microbarom (SFM, with peaks at 12-30s) is observed only under excellent storm conditions during the austral local winter. The strength of both DFM and SFM are strongly related to the seasons, but presumably also to the local sea-ice conditions in vicinity of the station.

Microseism / microbaroms are a useful proxy for characterizing ocean wave climate and global storm intensity, complementing other measurements such as ocean surface and satellite images. Continuous monitoring by seismograph and infrasound networks in Antarctica contribute strongly to the global seismic 
network and the test-ban treaty network in the high southern latitudes, and to the Pan-Antarctic Observations System.

\section{Acknowledgements}

We would like to express our sincere appreciation for many collaborators to the observations at SYO. We also thank all the members of the Antarctic programmes of the International Polar Year, such as POLENET (Prof. Terry Wilson of the Ohio State University, and other members), as well as the Japanese Antarctic Research Expeditions (JARE; Prof. Kazuyuki Shiraishi, Director-General of NIPR, and many other members). Infrasound observation at SYO was partially supported by the Ministry of Education, Science, Sports and Culture, Grant-in-Aid for Young Scientists (B) 19740265, 2007 (P.I. for Dr. Yoshiaki Ishihara). The authors would like to express sincere appreciation to Dr. Melanie Grob of the University of Alberta, and Dr. Anya Reading of the University of Tasmania, for their critical reading and giving many useful comments. We would also like to express sincere appreciation to Prof. Michael J. Hambrey of Aberystwyth University, for his efforts relating to the editorial matters for "Special Publication of the Geological Society - Antarctic Earth Surface Processes and Paleoenvironments".

\section{References}

Anandakrishnan, S. \& Alley, R. B. 1997. Tidal forcing of basal seismicity of ice stream C, West Antarctica, observed far inland. J. Geophys. Res., 102, 15,183-15,196.

Anandakrishnan, S., Voigt, D. E., Alley, R. B. \& King, M. A. 2003. Ice stream D flow speed is strongly modulated by the tide beneath the Ross Ice Shelf. Geophys. Res. Lett., 30, doi:10.1029/2002GL016329.

Aoyama, Y. \& Kanao, M. 2010. Seismological Bulletin of Syowa Station, Antarctica, 2008. JARE Data Report, 317 (Seismology 44), 1-85.

Ardhuin F., stutzmann, E., Schimmel, M. \& Mangeney, A. 2011. Revealing ocean wave sources of seismic noise. J. Geophys. Res., 116, C09004, doi:10.1029/2011JC006952.

Aster, R., McNamara, D. \& Bromirski, P. 2008. Multidecadal climate-induced variability in microseisms. Seismol. Res. Lett., 79, 194-202, doi:10.1785/gssrl.79.2.194.

Bohnenstiehl, D. R., Dziak, R. P., Parlk, M. \& Matsumoto, H. 2005. Seismicity of the polar seas: The potential for hydroacoustic monitoring of tectonic and volcanic processes. the 12th Seoul Inter. Sympo. on Polar Sci., 11-14, May 17-19, Ansan, Korea.

Bromirski, P. D. 2009. Earth vibrations. Science, 324, 1026-1027.

Butler, R. \& Anderson, K. 2008. Global Seismographic Network (GSN). IRIS Report, 6-7.

Dziak, R. P., Parlk, M., Lee, W. S., Matsumoto, H., Bohnenstiehl, D. R., \& Haxel, J. H. 2009. Tectonomagmatic activity and ice dynamics in the Bransfield Strait back-arc basin, Antarctica. the 16th Inter. Sympo. on Polar Sci., 59-68, June 10-12, Incheon, Korea. 
Eto, T. 1962. On the electromagnetic seismographs at Syowa Base, Antarctica. Antarct. Rec., 14, 48-50.

Grob, M., Maggi, A. \& E. Stutzmann, E. 2011. Observations of the seasonality of the Antarctic microseismic signal, and its association to sea ice variability. Geophys. Res. Lett., 38, L11302, doi:10.1029/2011GL047525.

Hagiwara, T. 1958. A note on the theory of the electromagnetic seismograph. Bull. Earthq. Res. Inst., 36, 139164.

Hansen, S. E., Nyblade, A. A., Heeszel, D. S., Wiens, D. A., Shore, P. \& Kanao, M. 2010. Crustal Structure of the Gamburtsev Mountains, East Antarctica, from S-wave Receiver Functions and Rayleigh Wave Phase Velocities. Earth Planet. Sci. Lett., 10.1016/j.eps1.2010.10.022.

Hatherton, T. 1960. Microseisms at Scott Base. Geophys. Jour., 3, 381-405.

Hedlin, M. \& Alcoverro, B. 2005. The use of impedance matching capillaries for reducing resonance in rosette infrasonic spatial filters. J. Acoust. Soc. Am., 117, 1880-1888.

Ishihara, Y., Furumoto, M., Sakai, S. \& Tsukuda, S. 2004. The 2003 Kanto large bolide's trajectory determined from shockwaves recorded by a seismic network and images taken by a video camera. Geophys. Res. Lett., 31, L14702.

Ishihara, Y., Yamamoto, M. \& Kanao, M. 2009. Current Status of Infrasound Pilot Observation at Japanese Islands and SYOWA Antarctica, and Development of New Infrasound Sensor using Optical Sensing Method. AGU Fall 2009 Meeting, San Francisco, A13D-0244,.

Iyemori, T., Nose, M., Han, D. S., Gao, Y., Hashizume, M., Choosakul, N., Shinagawa, H., Tanaka, Y., Utsugi, M., Saito, A., McCreadie, H., Odagi, Y. \& Yang, F. 2005. Geomagnetic pulsations caused by the Sumatra earthquake on December 26, 2004. Geophys. Res. Lett, 32, L20807, doi:10.1029/2005GL024083.

Kanao, M., Maggi, A., Ishihara, Y., Yamamoto, M.-Y., Nawa, K., Yamada, A., Wilson, T., Himeno, T., Toyokuni, G., Tsuboi, S., Tono, Y. \& Anderson, K. 2012. Interaction on Seismic Waves between Atmosphere - Ocean - Cryosphere and Geosphere in Polar Region. In: Kanao, M., (eds) Seismic Waves Research and Analysis -,InTech Publisher, Rijeka, 1-20.

Kanao, M. 2010. Detection Capability of Teleseismic Events Recorded at Syowa Station, Antarctica - 1987 2007-. Antarct. Rec., 54, 11-31.

Kanao, M., \& Kaminuma, K. 2006. Seismic activity associated with surface environmental changes of the Earth system, East Antarctica. In: Futterer, D. K., Damaske, D., Kleinschmidt, G., Miller, H. \& Tessensohn, F. (eds) Antarctica: Contributions to global earth sciences. Springer-Verlag, Berlin Heidelberg New York, 361-368.

Kanao, M., Nogi, Y. \& Tsuboi, S. 2006. Spacial distribution and time variation in seismicity around Antarctic Plate - Indian Ocean. Polar Geosci., 19, 202-223.

MacAyeal, D., Okal, E., Aster, R. \& Bassis, J. 2009. Seismic Observations of Glaciogenic Ocean Waves on Icebergs and Ice Shelves. J. Glaciology, 55, 193-206. 
Muller, C. \& Eckstaller, A. 2003. Local seismicity detected by the Neumayer seismological network, Dronning Maud Land, Antarctica: tectonic earthquakes and ice-related phenomena. IX Intern. Sympo. Antarc. Earth Sci. Programme and Abstracts, 236.

Nawa, K., Suda, N., Satake, K., Sato, T., Doi, K., Kanao, M. \& Shibuya, K. 2007. Loading and gravitational effects of the 2004 Indian Ocean tsunami at Syowa Station, Antarctica. Bull. Seis. Soc. Am., 97, S271-278, doi:10.1785/0120050625.

Nettles, M. \& Ekström, G. 2010. Glacial earthquakes in Greenland and Antarctica. Ann. Rev. Earth Plan. Sci., 38, 467-491.

Reading, A. M. 2006. On seismic Strain-Release within the Antarctic Plate. In: Futterer, D. K., Damaske, D., Kleinschmidt, G., Miller, H. \& Tessensohn, F. (eds) Antarctica: Contributions to global earth sciences. Springer-Verlag, Berlin Heidelberg New York, 351-356.

Reading, A. M. 2007. The seismicity of the Antarctic Plate. In: Stein, S. \& Mazzotti, S. (eds) Continental Intraplate Earthquakes: Science, Hazard and Policy Issues. Geological Society of America Special Paper, 425, 285-298.

Stutzmann, E., Schimmel, M., Patau, G. \& Maggi, A. 2009. Global climate imprint on seismic noise. Geochem. Geophys.Geosyst., 10, Q11004, doi:10.1029/2009GC002619.

Ushio, S. 2003. Frequent sea-ice breakup in the Lützow-Holmbukta, Antarctica, based on analysis of sea ice condition from 1980 to 2003. Antarct. Rec., 47, 338-348.

Waxler, R. \& Gilbert, K. E. 2006. The radiation of atmospheric microbaroms by ocean waves. J. Acoust. Soc. Am., 119 , 2651-2664.

Wielandt, E. \& Steim, J. M. 1986. A digital very-broad-band seismograph. Ann. Geophys., 4, 227-232.

Wiens, D. A. 2007. Broadband Seismology in Antarctica: Recent Progress and plans for the International Polar Year. Proc. Inter. Symp. -Asian Collaboration in IPY 2007-2008-, Tokyo, 21-24. 


\section{Figure Captions}

Fig. 1. Global map showing the Federation of Digital Seismological Network (modified after Butler and Anderson, 2008). Several regional networks developed by involved nations are indicated; such as IRIS, Geoscope, Geophone, Japan. Syowa Station (SYO) in East Antarctica is pointed out by red broken arrow.

Fig. 2. Schematic illustration of atmosphere - ocean - solid earth environments in Antarctic margins and Southern Ocean. Infrasound and seismic waves propagate from the source regions in Southern Ocean (SFM) and continental shelf area (DFM) to the margins of Antarctic continent; and recorded by Chaparral infrasound sensor as well as broadband seismometer (STS-1) at SYO.

Fig. 3. a) Map of global seismic network stations in Antarctica, including SYO. b) Earth science laboratory at SYO, where continuous monitoring takes place. c) A three-component broadband seismometer (STS-1; behind) and short period seismometers (HES; front) in the seismographic hut at SYO. d) Examples of short period analogue records during austral summer (January 19, 1997; 30 min. data; vertial component HES seismograph). e) Examples of analogue records during austral winter (July 16, 1997; 30 min. data; vertical component HES seismograph). Microseisms are clearly visible in the austral summer data.

Fig. 4. The power spectral densities (PSD) of the vertical broadband seismograph (STS-1V) at SYO for November 22, 2010. (Left) one day of data. (Right) 6 hours of data, corresponding to the shadowed area of the left figure. A teleseismic event (Northern NZ, Mw=5.9) is clearly recorded on the seismographs. The frequency range of DFM is indicated by the red arrow.

Fig. 5. Power spectral densities (PSD) of the broadband seismograph (STS-1V) at SYO, for a whole season in 2004. Predominant frequencies corresponding to SFM and DFM are indicated by blue and red arrows, respectively (modified after Grob et al, 2011; Kanao et al., 2012).

Fig. 6. Microseismic spectra over a year in 2007 for stations SYO and CASY. Each curve represents the seismic noise spectra for one day, colour-coded by day of the year (see legend). Primary (SFM) and secondary (DFM) microseisms are outlined by grey boxes. Summer and winter time peak frequencies are highlighted in red and blue, respectively (modified after Grob et al, 2011).

Fig. 7. Top: A global distribution map of the Comprehensive Nuclear Test-Ban Treaty Organization infrasound network. Bottom: (a) Photograph of Syowa Station (SYO) in East Ongul Island, in Lützow-Holm Bay. (b) The infrasound sensor inside the wood box installed at SYO. (c) Infrasound station distribution in Antarctica. 
Fig. 8. One day PSD of infrasound data at SYO in January 02, 2010. The DFM is indicated by a red arrow. High-frequency signals above $10 \mathrm{~Hz}$ are identified clearly, with labelled by the dotted green square.

Fig. 9. Power spectral densities (PSD) of the infrasound signals in April - December 2008, from the start of pilot observation at SYO. The grey-coloured time zones imply the lack of data, otherwise any kinds of errors during the PSD processing. Predominant frequencies corresponding to SFM and DFM are indicated by blue and red arrows, respectively. Characteristic harmonic signals more than $10 \mathrm{~Hz}$ are represented by the dotted green square.

Fig. 10. PSD of infrasound signals in 2009. The grey-coloured time zones imply the lack of data, otherwise any kinds of errors during the PSD processing. Predominant frequencies corresponding to SFM and DFM are indicated by blue and red arrows, respectively. Characteristic harmonic signals more than $10 \mathrm{~Hz}$ are identified by the dotted green square. 